\title{
AVALIAÇÃO DE ALGUNS FATORES INFLUENTES NA VELOCIDADE ULTRA-SÔNICA NA MADEIRA
}

\author{
Leandro Calegari ${ }^{1}$, Diego Martins Stangerlin ${ }^{2}$, Elio José Santini ${ }^{3}$, Clóvis Roberto Haselein ${ }^{3}$, \\ Darci Alberto Gatto ${ }^{4}$, Paulo Inácio Obregon do Carmo ${ }^{5}$, Luiz Carlos Pinto da Silva Filho ${ }^{6}$
}

\footnotetext{
${ }^{1}$ Eng. Florestal, M.Sc., Doutorando em Ciência Florestal, UFV, Viçosa, MG, Brasil - leandrocalegari@yahoo.com.br ${ }^{2}$ Eng. Florestal, Mestrando em Engenharia Florestal, UFSM, Santa Maria, RS, Brasil - diego_stangerlin@yahoo.com.br ${ }^{3}$ Eng. Florestal, Dr., Depto. de Ciências Florestais, UFSM, Santa Maria, RS, Brasil - santinie@ccr.ufsm.br - haseleic@ccr.ufsm.br ${ }^{4}$ Eng. Florestal, Dr., Engenharia Industrial Madeireira, UFPEL, Capão do Leão, RS, Brasil - darcigatto@yahoo.com.br ${ }^{5}$ Eng. Civil, M.Sc., Laboratório de Materiais e Construção Civil, UFSM, Santa Maria, RS, Brasil - obregon@ctlab.ufsm.br ${ }^{6}$ Eng. Civil, Dr., Depto. de Engenharia Civil, UFRGS, Porto Alegre, RS, Brasil - lcarlos@cpgec.ufrgs.br
}

Recebido para publicação: 07/07/2007 - Aceito para publicação: 15/05/2008

\begin{abstract}
Resumo
O ultra-som vem sendo utilizado para a detecção de defeitos em diversos materiais homogêneos desde a década de 70 do século XX. No entanto, na madeira, material heterogêneo, sua utilização é recente no Brasil. A propagação das ondas ultra-sônicas na madeira é influenciada por diversos fatores, tais como a espécie florestal, o tipo de transdutor e a temperatura do meio. Com o objetivo de estudar a influência desses fatores, testou-se o uso de transdutores de pontos secos, sendo que os tratamentos basearam-se na combinação de madeiras de diferentes espécies (Pinus elliottii Engelm. e Eucalyptus grandis Hill ex Maiden) e temperaturas de secagem $\left(20,40\right.$ e $\left.70{ }^{\circ} \mathrm{C}\right)$. Os modelos apresentaram influência significativa do teor de umidade, da massa específica e da temperatura de secagem sobre a estimativa da velocidade ultra-sônica. Ocorreu aumento da velocidade com a redução do teor de umidade, sendo essa relação válida desde a madeira verde até o final do processo de secagem. $\mathrm{O}$ eucalipto foi a espécie que apresentou melhor resultado, apresentando coeficiente de determinação de $71 \%$. O aumento da velocidade ultra-sônica ocorreu de modo diretamente proporcional à massa específica na madeira de pinus, porém inversamente na de eucalipto. A velocidade ainda apresentou tendência de redução com o aumento da temperatura de secagem. Apesar da existência de transdutores específicos a serem utilizados na madeira, há necessidade do conhecimento das diversas características desse material na propagação das ondas ultra-sônicas, principalmente quando considerada a grande diversidade de espécies florestais existentes nos países tropicais, como é o caso do Brasil.

Palavras-chave: Transdutores de pontos secos; ultra-som; secagem da madeira.
\end{abstract}

\begin{abstract}
Evaluation of some influential factors in the ultrasonic velocity in the wood. Ultrasound has been used for detection of defects in different homogeneous materials since the 1970s. In wood, as a heterogeneous material, its use is recent in Brazil. Ultrasonic wave propagation is influenced by several factors such as the forest species, type of transducer and environmental temperature. Aiming at studying the influence of such factors, this research involved the use of point-contact transducers. Wood of two different species (Pinus elliottii Engelm. and Eucalyptus grandis Hill ex Maiden) were dried at constant temperatures of 20,40 , and $70^{\circ} \mathrm{C}$. The models proposed for analysis showed significant influence of moisture content, specific mass and drying temperatures on ultrasonic velocity. Increase of velocity occurred due to a reduction of moisture content, over the range of green wood to the end of the drying process. Eucalyptus had the best results, with a determination coefficient of $71 \%$. The increase of ultrasonic velocity was directly proportional to the specific mass on pine wood; but inversely proportional to that for eucalyptus one. The ultrasonic velocity also showed a tendency to decrease with the increase of drying temperature. In spite of the existence of specific transducers to be used in the wood, knowledge of the several characteristics of this material in the propagation of the ultrasonic waves is needed, mainly when the great diversity of remaining forest species in tropical countries is taken into account, as it is the case of Brazil. Keywords: Point-contact transducers; ultrasound; wood drying.
\end{abstract}




\section{INTRODUÇÃO}

Uma vez que as técnicas de ultra-som para o monitoramento da qualidade da madeira são relativamente novas no Brasil, tendo sido iniciadas em 1997, poucas são as pesquisas, até o presente momento, envolvendo seu uso para o controle de processos (ALVES FILHO, 2003).

A velocidade de propagação das ondas ultra-sônicas está intrinsecamente relacionada com as propriedades elásticas dos materiais sólidos, sendo função da raiz quadrada da razão entre o módulo de elasticidade dinâmico e a massa específica desse material.

Considerando o tipo mais comum de sistema de medida da propagação da onda de ultra-som em um material, um sinal elétrico é emitido por um gerador, transmitido por meio de cabos e transformado em pulso mecânico por um sensor ao atingir o material em teste. Esse pulso atravessa o corpo-de-prova e é recuperado na face oposta à de transmissão por outro sensor, revertendo-o novamente em sinal elétrico. A medição do tempo decorrido entre a emissão e a recepção do sinal e da distância entre os sensores permite o cálculo da velocidade de propagação da onda. Esse sensor responsável pela emissão e recepção das ondas denomina-se transdutor, que se apresenta nos mais variados tipos e tamanhos. Os transdutores mais comuns são os de faces planas, que requerem o uso de acoplantes (óleo, gel, graxa ou vaselina) que devem ser aplicados entre a superfície da peça em ensaio e o transdutor, a fim de reduzir erros, uma vez que a ocorrência de ar entre esses meios proporciona maior tempo de propagação da onda (velocidade da onda ultra-sônica é menor no ar), reduzindo sua velocidade.

Nesvijski (2003) descreveu como desvantagens do uso dos transdutores de faces planas que os acoplantes proporcionam instabilidade das repetições durante os testes, não podem ser utilizados em superfícies ásperas ou curvas e que as alterações da distância entre os transdutores emissores-receptores aumentam as possibilidades de erro. Segundo o mesmo autor, esses problemas poderiam ser evitados pela estabilização do contato durante os testes, utilizando-se transdutores com pontos secos, os quais podem ser possíveis pelo uso de extensores de ondas (Figura 1). Devido à rapidez, seu uso permite ainda aumentar a precisão dos dados pelo aumento do número de repetições (LORENZI, 2000).

Uma vez que o teor de umidade da madeira é um dos fatores de influência sobre a velocidade de propagação das ondas ultra-sônicas, pesquisadores como Dyk; Rice (2005), Brashaw et al. (2004), Gonçalves; Costa (2002), Simpson (1998) e Simpson; Wang (2001) correlacionaram a velocidade ultrasônica ao teor de umidade, explorando esse ponto para o monitoramento do teor de umidade da madeira durante o processo de secagem. Uma das suas principais características é a determinação do teor de umidade da madeira acima do ponto de saturação das fibras (PSF), comumente considerado de $28 \%$, o que não é observado para a maioria das alternativas tecnológicas testadas até o presente momento, visando o controle do processo de secagem. Medidores de umidade baseados na resistência elétrica (mais utilizados), por exemplo, apenas funcionam precisamente quando a madeira apresenta umidade inferior ao PSF.

Inúmeras pesquisas e aplicações práticas vêm sendo realizadas com equipamentos ultra-sônicos específicos para a madeira em países da Europa e nos Estados Unidos. No Brasil, no entanto, observa-se uma carência de pesquisas para o desenvolvimento de novos transdutores com tecnologia nacional. No que se refere aos transdutores, é muito importante o uso da freqüência adequada às características do material e ao tamanho da peça avaliada.

Além das características dos transdutores e a influência do teor de umidade, no caso da madeira, a propagação das ondas ultra-sônicas é ainda influenciada por outros fatores, tais como propriedades anatômicas (espécie), físicas (massa específica), morfológicas (tipos de lenhos e ângulo da grã), presença de defeitos (nós e rachaduras) e condições do meio (temperatura e umidade relativa).

Nesse sentido, este trabalho teve como objetivo analisar a eficiência dos transdutores de pontos secos para a estimativa da velocidade ultra-sônica em madeiras de diferentes espécies (Pinus elliottii Engelm. e Eucalyptus grandis Hill ex Maiden) submetidas a secagem sob diferentes temperaturas (20, 40 e $\left.70^{\circ} \mathrm{C}\right)$.

\section{MATERIAIS E MÉTODOS}

Foram utilizadas madeiras de Pinus elliottii Engelm. (pinus) e Eucalyptus grandis Hill ex Maiden (eucalipto), de 30 e 12 anos de idade, respectivamente. Utilizaram-se três árvores para cada uma 
das espécies, sendo usada a primeira tora $(2,5 \mathrm{~m})$ obtida a partir da base de cada uma delas. De cada tora retirou-se uma prancha central $(3,5 \mathrm{~cm}$ de espessura) paralelamente à medula. De cada prancha foram retiradas duas tábuas $(10 \mathrm{~cm}$ de largura) localizadas em lados opostos da medula. Cada tábua foi seccionada transversalmente para obtenção das amostras de secagem $(25 \times 10 \times 3,5 \mathrm{~cm})$.

A quantidade total de amostras de secagem, para cada espécie, foi dividida aleatoriamente e submetida a três temperaturas constantes de secagem: 20,40 e $70{ }^{\circ} \mathrm{C}$. Foram descartadas as amostras de secagem que visualmente apresentaram defeito de secagem, tal como rachaduras, evitando-se a influência desse fator na velocidade de propagação das ondas ultra-sônicas.

Portanto, os tratamentos basearam-se na combinação das duas espécies e três temperaturas de secagem, constituindo um delineamento fatorial (Tabela 1).

Tabela 1. Tratamentos avaliados durante o experimento.

Table 1. Evaluated treatments in the experiment.

\begin{tabular}{lccc}
\hline Tratamento & Espécie & Temperatura de secagem $\left({ }^{\mathbf{}} \mathbf{C}\right)$ & Número de amostras \\
\hline 1 & Pinus elliottii & 20 & 35 \\
2 & Pinus elliottii & 40 & 34 \\
3 & Pinus elliottii & 70 & 35 \\
4 & Eucalyptus grandis & 20 & 36 \\
5 & Eucalyptus grandis & 40 & 38 \\
6 & Eucalyptus grandis & 70 & 36 \\
\hline
\end{tabular}

Além das amostras de secagem, foram ainda seccionadas 3 amostras de controle $(2,5 \times 10 \times 3,5$ $\mathrm{cm})$ de cada uma das tábuas, que foram imediatamente pesadas e submetidas a secagem em estufa $\left(103^{\circ} \mathrm{C}\right)$, para a obtenção do teor de umidade inicial das tábuas (base seca). Essas amostras de controle foram utilizadas somente para a determinação do final do processo das amostras submetidas a secagem (amostras de secagem), conforme procedimento utilizado por Santini (1996) e Calegari (2006).

A secagem a $20{ }^{\circ} \mathrm{C}$ foi efetuada em câmara climatizada (umidade relativa UR $=65 \%$ ), e as secagens a 40 e $70{ }^{\circ} \mathrm{C}$, em estufa com circulação forçada de ar. Para a determinação do tempo de propagação das ondas ultra-sônicas, utilizou-se aparelho emissor acoplado a transdutores de pontos secos (freqüência de $50 \mathrm{kHz}$ ). Antes de cada série de ensaio, o aparelho emissor de ultra-som foi calibrado, conforme especificado no manual, por meio de um cilindro calibrador metálico, fornecido juntamente com o equipamento.

Conforme apresentado na figura 1 , os transdutores eram constituídos por extensores de ondas cônicos e eram acoplados em suporte, que também era utilizado para apoio das mãos. Esse conjunto (suporte e transdutores com extensores de ondas) é um dispositivo patenteado, sendo que o ângulo dos transdutores com relação à vertical apresenta valor fixo $\left(30^{\circ}\right)$.

O tempo de propagação das ondas ultra-sônicas foi obtido no centro das amostras, considerando a direção longitudinal da madeira. Uma reta foi demarcada para que ambos os pontos de contato ficassem perfeitamente alinhados, sendo então pressionados sobre a reta, apenas em contato superficial (Figura 1). Não se levou em consideração se os pontos de contato ficaram sobre o lenho inicial ou tardio. Uma vez que esse procedimento foi repetitivamente realizado durante a secagem das amostras, atentou-se para que os pontos de contato fossem acoplados sempre sobre o mesmo local da reta em que foram acoplados na medição anterior. Tomou-se o cuidado de que a pressão aplicada aos transdutores fosse sempre a mesma.

Posteriormente, a velocidade de propagação das ondas ultra-sônicas, em $\mathrm{m} \cdot \mathrm{s}^{-1}$, foi calculada pela razão entre o comprimento do trecho percorrido pela onda (distância fixa entre os pontos secos de $12 \mathrm{~cm}$ ) e o tempo de propagação $(\mu \mathrm{s})$.

Durante a secagem, as amostras eram repetitivamente retiradas da estufa para a determinação do tempo de propagação da onda ultra-sônica, sendo imediatamente repostas. Simultaneamente, também era realizada a pesagem de cada amostra de secagem, para a posterior determinação do seu teor de umidade no momento exato de cada teste ultra-sônico. O processo de secagem foi finalizado quando as amostras atingiram $12 \%$ de umidade (base seca). Finalmente, após a obtenção do peso seco ( $0 \%$ de umidade) das amostras, em estufa de circulação forçada de ar, calculou-se o teor de umidade atual (umidade correspondente ao momento exato de cada pesagem) e determinou-se o tempo de propagação das ondas ultra-sônicas. 


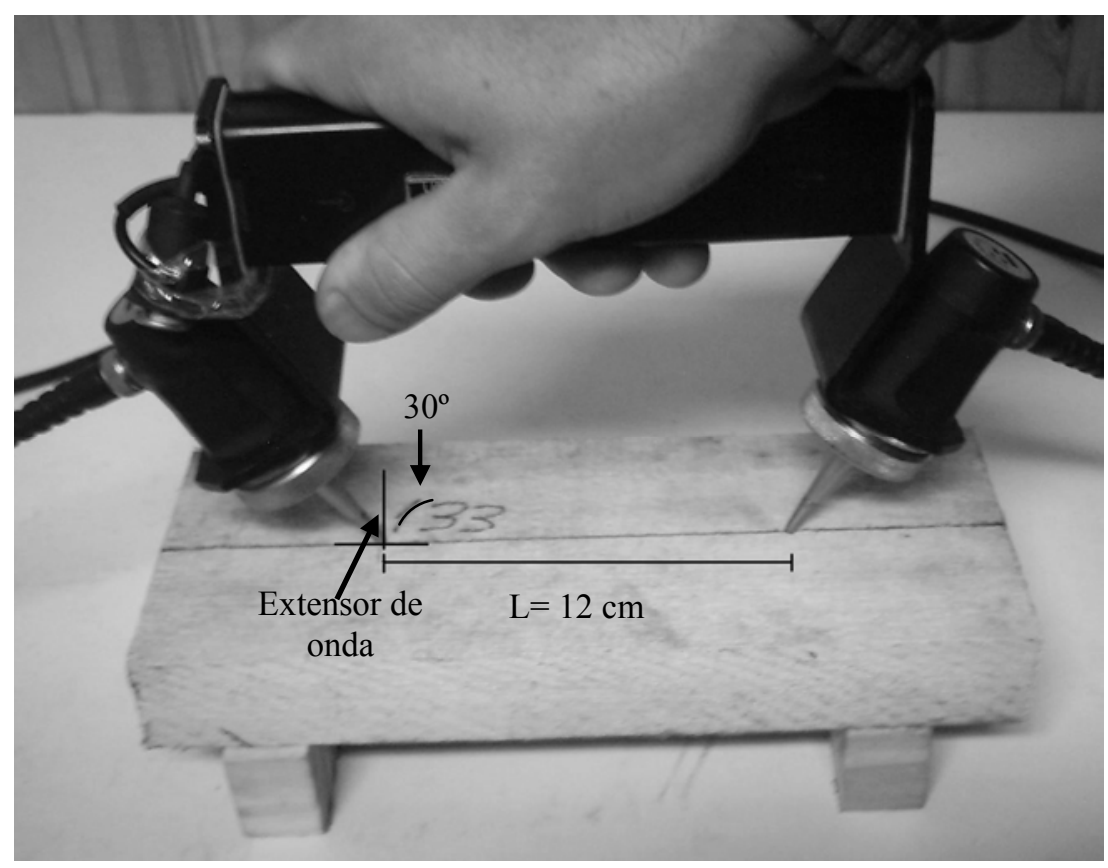

Figura 1. Determinação do tempo de propagação da onda ultra-sônica na madeira utilizando transdutores com pontos $\operatorname{secos}(\mathrm{L}=$ distância entre os pontos de contato).

Figure 1. Determination of time of propagation of the ultrasonic wave in the wood using point-contact transducers ( $\mathrm{L}=$ distance between the point contacts).

As amostras foram então colocadas em câmara climatizada $\left(\mathrm{T}=20{ }^{\circ} \mathrm{C}\right.$ e UR $\left.=65 \%\right)$ até atingirem peso constante, indicando terem alcançado o teor de umidade de equilíbrio (12\%). Nessa condição, além da sua pesagem, mediram-se também as dimensões das amostras, a fim de se calcular sua massa específica (razão entre massa seca e volume a 12\% de umidade). Dessa forma, todos os cálculos foram realizados considerando a massa específica básica da madeira a $12 \%$ do teor de umidade.

Os resultados experimentais foram estatisticamente analisados por meio de análise de regressão, selecionando-se os modelos que melhor estimassem a velocidade ultra-sônica em função do teor de umidade, da temperatura de secagem e da massa específica das amostras. A espécie da madeira, sendo uma variável qualitativa, foi comparada a partir dos modelos gerados a partir das variáveis anteriores (quantitativas). As análises foram realizadas considerando-se três faixas de teores de umidade: superiores ao ponto de saturação das fibras teórico $(\mathrm{PSFt}=28 \%$ ), inferiores ao PSFt, e desde a madeira verde até a seca $(\mathrm{TU}=12 \%)$. As medidas de adequação e seleção dos modelos de regressão foram feitas através da análise do coeficiente de determinação ajustado $\left(\mathrm{R}_{\mathrm{aj}}{ }^{2}\right)$, do erro padrão da estimativa $\left(\mathrm{S}_{\mathrm{xy}}\right)$, do valor de $\mathrm{F}$ e da análise visual dos resíduos, sendo considerados mais adequados os modelos de maiores $\mathrm{R}_{\mathrm{aj} .}{ }^{2} \mathrm{e} \mathrm{F}$, menor $\mathrm{S}_{\mathrm{xy}}$ e melhor distribuição dos resíduos.

\section{RESULTADOS E DISCUSSÃO}

A velocidade das ondas ultra-sônicas no sentido longitudinal, obtida pelos transdutores de pontos secos, situou-se entre 2210 e $2750 \mathrm{~m} . \mathrm{s}^{-1}$, correspondendo, da mesma forma que observada por Lorenzi (2000), apesar de este autor ter avaliado o concreto, aproximadamente à metade da obtida quando do uso de transdutores de faces planas (SIMPSON, 1998; GONÇALVES; COSTA, 2002; CALEGARI, 2006).

Transdutores de pontos secos não geram ondas direcionadas, proporcionando maior tempo de propagação quando comparadas às ondas geradas por meio de transdutores de faces planas. Além desse fator, a forma, o material de fabricação e/ou o ângulo de inclinação do extensor de ondas também contribuem para a alteração do tipo de onda gerada pelo transdutor, alterando também sua velocidade de 
propagação (NESVIJSKI, 2003).

Apesar de este trabalho ter apresentado baixa velocidade de propagação das ondas ultra-sônicas pelo emprego de transdutores de pontos secos, existem resultados de pesquisas (PUCCINI, 2002; COSTA, 2005) que descrevem altos valores de velocidade obtidos por transdutores de pontos secos, próximos aos observados por transdutores de face plana. Os baixos resultados obtidos neste trabalho podem sugerir que as ondas não eram efetivamente longitudinais, o que foi ocasionado pelo ângulo formado entre os transdutores e a superfície da madeira. Uma onda, ao incidir em ângulo com as fibras, não gera onda longitudinal pura, ou seja, há componentes longitudinais e transversais, a não ser que o ângulo seja calculado para gerar uma onda puramente longitudinal. No caso deste estudo, o ângulo pode ter proporcionado geração de uma onda de superfície, que apresenta baixa velocidade de propagação, principalmente considerando a pequena distância entre os transdutores.

Os modelos que estimam a velocidade ultra-sônica em função do teor de umidade da madeira, incluindo a influência da temperatura de secagem e a massa específica da madeira, para diferentes faixas de teores de umidade, são mostrados na tabela 2 .

Tabela 2. Estimativa da velocidade ultra-sônica em função do teor de umidade da madeira, da massa específica e da temperatura de secagem, para as diferentes espécies e faixas de teores de umidade.

Table 2. Estimate of ultrasonic velocity as a function of moisture content of the wood, specific mass and drying temperature, for different species and ranges of moisture content.

\begin{tabular}{|c|c|c|c|c|c|}
\hline Espécie & $\begin{array}{c}\text { Faixa } \\
\text { de TU }\end{array}$ & Equação de regressão( ${ }^{(2)}$ & $\begin{array}{l}R_{\text {aj. }}{ }^{2} \\
(\%)\end{array}$ & $\begin{array}{c}\mathbf{S}_{\mathrm{yx}} \\
(\mathbf{m} / \mathbf{s})\end{array}$ & F \\
\hline \multirow{3}{*}{$\begin{array}{l}\text { Pinus } \\
\text { elliottii }\end{array}$} & $12 \leq \mathrm{TU} \leq 100$ & $\begin{array}{c}\mathrm{V}=2241,3-5,4817 . \mathrm{TU}+ \\
0,02344 . \mathrm{TU}^{2}-0,73095 . \mathrm{T}+908,7 * \mathrm{D}\end{array}$ & 61,1 & 66,4 & $332,43 * *$ \\
\hline & $12 \leq \mathrm{TU} \leq 28$ & $\begin{array}{c}\mathrm{V}=844,64-5,6104 . \mathrm{TU}-0,8028 . \mathrm{T}+ \\
6559 . \mathrm{D}-5611,73 . \mathrm{D}^{2}\end{array}$ & 31,1 & 62,5 & $37,61^{* *}$ \\
\hline & $28<\mathrm{TU} \leq 100$ & $\begin{array}{c}\mathrm{V}=2175,62-2,66846 . \mathrm{TU}- \\
0,623866 . \mathrm{T}+879,557 . \mathrm{D}\end{array}$ & 39,6 & 68,5 & $103,38^{* *}$ \\
\hline \multirow{3}{*}{$\begin{array}{l}\text { Eucalyptus } \\
\text { grandis }\end{array}$} & $12 \leq \mathrm{TU} \leq 100$ & $\begin{array}{l}\mathrm{V}=3243,39-1,98508 . \mathrm{TU}- \\
0,0196598 . \mathrm{TU}^{2}-1072,61 . \mathrm{D}\end{array}$ & 71,5 & 59,9 & $864,91 * *$ \\
\hline & $12 \leq \mathrm{TU} \leq 28$ & $\begin{array}{c}\mathrm{V}=1476,2-3,32369 . \mathrm{TU}+6123,19 . \mathrm{D} \\
-7231,18 . \mathrm{D}^{2}\end{array}$ & 28,1 & 55,3 & $43,16^{* *}$ \\
\hline & $28<\mathrm{TU} \leq 100$ & $\begin{array}{c}\mathrm{V}=1556,57-4,45686 . \mathrm{TU}+ \\
6288,12 . \mathrm{D}-7663,81 . \mathrm{D}^{2}\end{array}$ & 67,5 & 60,1 & $472,30 * *$ \\
\hline
\end{tabular}

${ }^{1}$ TU: teor de umidade base seca $(\%) ;{ }^{2} \mathrm{~V}$ : velocidade ultra-sônica $(\mathrm{m} / \mathrm{s}) ; \mathrm{T}$ : temperatura de secagem $\left({ }^{\circ} \mathrm{C}\right) ;$ D: massa específica (razão entre massa seca e volume a $12 \%$ de umidade, em $\left.\mathrm{g} / \mathrm{cm}^{3}\right) ; \mathrm{R}_{\mathrm{aj}}{ }^{2}$ : coeficiente de determinação ajustado; $\mathrm{S}_{\mathrm{yx}}$ : erro padrão da estimativa; $\mathrm{F}$ : valor de $\mathrm{F}$ calculado (**: significativo ao nível de $1 \%$ de probabilidade de erro).

Para a madeira de ambas as espécies, observou-se que melhores ajustes de modelos ocorreram quando se considerou a variação de umidade da madeira desde verde até o final da secagem (de 100 a $12 \%$ ). Esse comportamento não corresponde ao observado quando foram utilizados transdutores de faces planas, sendo que melhores ajustes ocorreram desde a madeira seca até o PSF (SIMPSON, 1998; GONÇALVES; COSTA, 2002; CALEGARI, 2006). A grande influência do teor de umidade sobre o módulo de elasticidade nessa faixa seria responsável por essa variação significativa da velocidade ultrasônica. Portanto, teores de umidade superiores ao PSF proporcionaram menores variações da velocidade ultra-sônica e, conseqüentemente, piores ajustes matemáticos.

Durante a secagem da madeira, primeiramente ocorre perda da umidade na sua superfície, progredindo então para seu centro. Uma vez que os transdutores de pontos secos tendem a ficar restritos à superfície das amostras, o teor de umidade pode ser correspondente a esse local. Por esse motivo, o gradiente de teor de umidade da peça de madeira durante sua secagem deve apresentar maior influência quando do uso dos transdutores de pontos secos em comparação ao uso de transdutores de faces planas (geralmente utilizados na parte central das amostras), explicando esse comportamento anômalo. Ainda, o não-selamento das faces transversais das amostras durante sua secagem deve ter favorecido o agravamento desse problema. 
A madeira de eucalipto foi a que apresentou os melhores ajustes dos modelos, explicando 71,5\% dos dados. A maior variação ocorrida entre as amostras de pinus pode estar relacionada a dois fatores: o primeiro diz respeito ao fato de a própria madeira dessa espécie apresentar grande heterogeneidade, devido à maior distinção entre o lenho inicial e o tardio; e o segundo fator é a baixa dureza superficial dessa madeira, que favoreceu para um leve aprofundamento da superfície em contato com os pontos durante as repetitivas medições, enquanto que na madeira de eucalipto os pontos de contato ficaram restritos à superfície da madeira.

Para uma melhor análise da influência da temperatura de secagem, da massa específica e da espécie de madeira, foram gerados gráficos a partir dos modelos apresentados na tabela 2 (Figuras 2,3 e 4). Consideraram-se apenas os modelos incluindo a faixa total de teor de umidade, para ambas as espécies, devido aos melhores ajustes.

Observou-se o comportamento clássico do aumento da velocidade ultra-sônica à medida que o teor de umidade da madeira se reduz. Conforme descrito, a velocidade de propagação das ondas pela madeira é função da raiz quadrada da razão entre o módulo de elasticidade e a massa específica, portanto diretamente relacionada ao módulo de elasticidade, que é sensivelmente afetado pela umidade. Assim, alterações dessa variável influenciam significativamente a propagação das ondas.

A figura 2 apresenta, para cada espécie, a influência da temperatura de secagem. Foram mantidas fixas as massas específicas médias para cada espécie $\left(0,52\right.$ e $0,49 \mathrm{~g} \cdot \mathrm{cm}^{-3}$ para pinus e eucalipto, respectivamente).
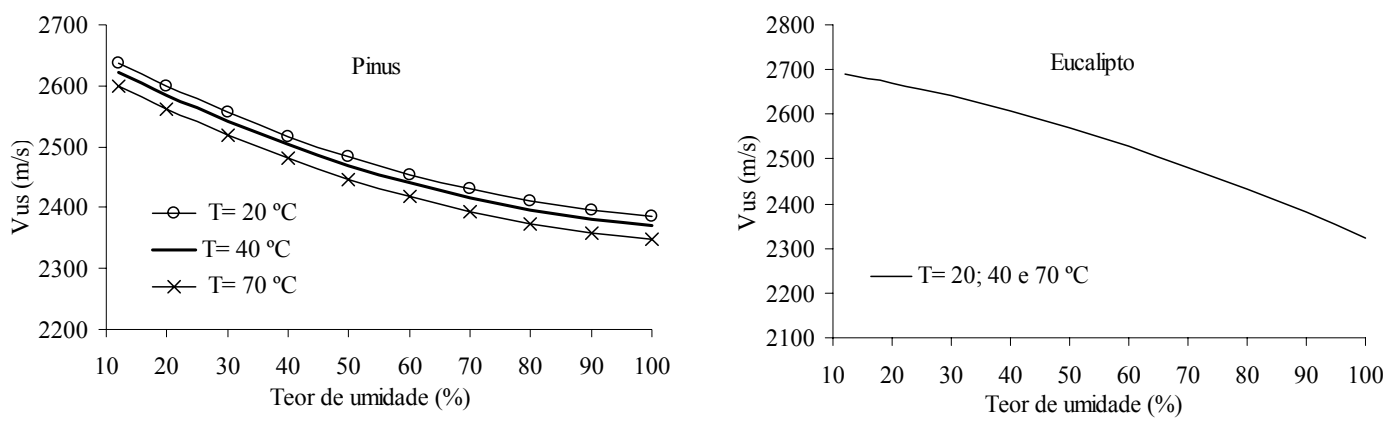

Figura 2. Efeito da temperatura de secagem (T) sobre a velocidade ultra-sônica (Vus) para madeiras de Pinus elliottii e Eucalyptus grandis determinadas com transdutores de pontos secos.

Figure 2. Influence of drying temperatures (T) on the ultrasonic velocity (Vus) for Pinus elliottii and Eucalyptus grandis wood obtained with point-contact transducers.

Conforme estabelecido por Green et al. (1999a), o módulo de elasticidade da madeira decresce com o aumento da temperatura. Já a velocidade ultra-sônica é diretamente proporcional ao módulo de elasticidade. Portanto, o aumento da temperatura de secagem proporciona redução da velocidade ultrasônica (Figura 2 - Pinus), da mesma forma que observado por Grundström (1998), Green et al. (1999b) e Bekhta et al. (2000).

No entanto, apesar de as propriedades da madeira e, conseqüentemente, da velocidade das ondas decrescerem quando a madeira é aquecida e aumentarem quando ela é esfriada, essa influência é reduzida, provável motivo pelo qual essa variável apresentou-se como não-significativa para a madeira de eucalipto (Figura 2 - Eucalipto).

Na figura 3 são apresentadas o efeito da massa específica para as espécies, considerando-se fixo o valor médio das três temperaturas analisadas $\left(43^{\circ} \mathrm{C}\right)$.

Quanto à massa específica, observou-se aumento proporcional da velocidade ultra-sônica com o aumento dessa propriedade na madeira de pinus. Já para a madeira de eucalipto, foi observado comportamento inverso (Figura 3).

Conforme Shimoyama (2005), madeiras de maior massa específica apresentam maior teor de substância madeira, portanto, menores espaços vazios, propiciando aumento da velocidade de propagação das ondas. Bartholomeu (2001), analisando duas espécies de dicotiledôneas - cupiúba (Goupia glabra Aubl.) e Eucalyptus citriodora Hook. - e uma de conífera (Pinus elliottii Engelm.), observou pequeno 
aumento da velocidade com o aumento da massa específica aparente. A explicação dada pelo autor é que a transferência de energia ultra-sônica está mais associada à estrutura celular da madeira do que à sua massa específica aparente. Wang et al. (2003), analisando madeira de Taiwania cryptomerioides Hay., observaram que, no sentido longitudinal, a velocidade tendeu a diminuir linearmente com o aumento da massa específica, e no sentido radial tendeu a aumentar.
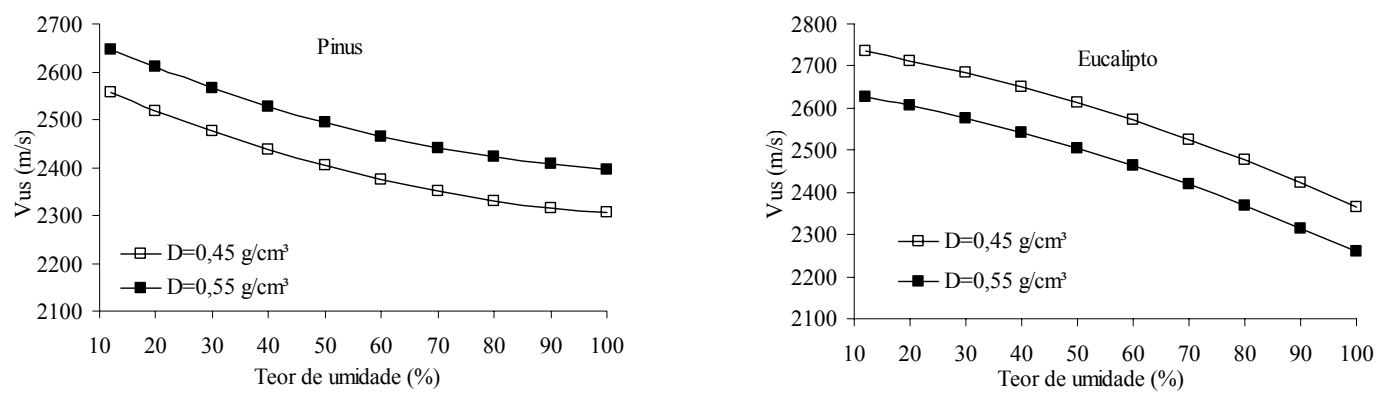

Figura 3. Efeito da massa específica (D) sobre a velocidade ultra-sônica (Vus) para madeiras de Pinus elliottii e Eucalyptus grandis determinadas com transdutores de pontos secos (temperatura de secagem $=43^{\circ} \mathrm{C}$ ).

Figure 3. Influence of specific mass (D) on the ultrasonic velocity (Vus) for Pinus elliottii and Eucalyptus grandis wood obtained with point-contact transducers (drying temperature $=43^{\circ} \mathrm{C}$ ).

Apesar de a massa específica ser o parâmetro mais prático utilizado para a determinação das propriedades de determinado material, o fator que realmente influencia na propagação da onda ultrasônica é a continuidade. Em um meio composto de bolas de aço adjacentes, por exemplo, sua elevada massa específica não garante uma elevada velocidade de propagação da onda, devido aos inúmeros pontos de descontinuidade. A madeira, por apresentar naturalmente elevada descontinuidade, não contribui para a efetiva propagação das ondas, justificando os baixos valores das regressões observadas inclusive neste trabalho. Adicionalmente, a pequena variação da massa específica observada neste estudo, combinada ao baixo ajuste dos modelos, não contribui de maneira eficiente para a análise dessa variável.

Com relação à influência da espécie, observou-se que a madeira de eucalipto proporcionou maior velocidade de propagação das ondas ultra-sônicas quando comparada à de pinus (Figura 4).

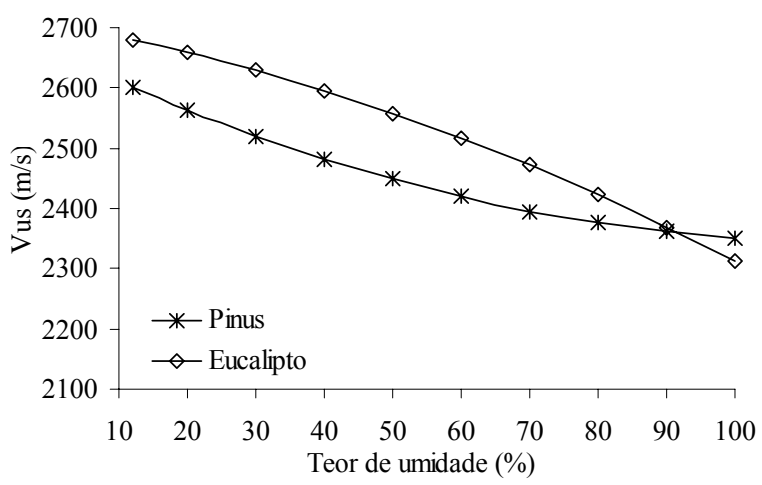

Figura 4. Efeito da espécie sobre a velocidade ultra-sônica (Vus) determinada com transdutores de pontos secos (temperatura de secagem $\mathrm{T}=43^{\circ} \mathrm{C}$ e massa específica $\mathrm{ME}=0,5 \mathrm{~g} . \mathrm{cm}^{-3}$ ).

Figure 4. Influence of species on the ultrasonic velocity (Vus) obtained with point-contact transducers (drying temperature $=43^{\circ} \mathrm{C}$ and specific mass $=0.50 \mathrm{~g} / \mathrm{cm}^{3}$ ). 
O efeito da espécie da madeira está diretamente relacionada às descontinuidades proporcionadas por sua constituição anatômica. Para Bucur (1988), considerando o sentido longitudinal da madeira, o aumento do comprimento das fibras favorece a propagação devido ao maior caminho contínuo da parede a ser percorrido pelas ondas. Assim, a contínua e uniforme estrutura das coníferas favorece o aumento da velocidade das ondas quando comparada às folhosas. No entanto, esse comportamento não foi observado neste trabalho.

Da mesma forma, Costa (2005) adotou tanto coníferas quanto folhosas em seu estudo, sendo que as massas específicas básicas seguiram a relação Eucalyptus citriodora Hook. > Goupia glabra Aubl. (cupiúba) > Ocotea porosa Nees (imbuia) > Araucaria angustifolia Bertol. (araucária) > Pinus elliottii Engelm. No entanto, as maiores velocidades de propagação foram determinadas para a araucária $(0,46$ g.cm $\left.{ }^{-3}\right)$, seguida da cupiúba $\left(0,70\right.$ g.cm $\left.{ }^{-3}\right)$, eucalipto $\left(0,94 \mathrm{~g} . \mathrm{cm}^{-3}\right)$, pinus $\left(0,40 \mathrm{~g} . \mathrm{cm}^{-3}\right)$ e, por último, a imbuia $\left(0,52 \mathrm{~g} \cdot \mathrm{cm}^{-3}\right)$. A velocidade foi semelhante para o pinus e o eucalipto, apesar da grande diferença de massa específica. Portanto, esse autor também não observou uma relação entre a espécie e a velocidade de propagação do ultra-som.

\section{CONCLUSÕES}

A velocidade de propagação das ondas ultra-sônicas, determinada com os transdutores de pontos secos, apresentou influência significativa com o teor de umidade da madeira durante sua secagem, sendo essa relação inversamente proporcional e válida à madeira desde verde até o final do processo de secagem.

Apesar da praticidade, o tipo de transdutor utilizado neste trabalho deve ser preferencialmente usado em madeiras duras e menos heterogêneas, como as do gênero Eucalyptus. Entretanto, transdutores de pontos secos com configurações adequadas já vêm sendo utilizados em madeiras de coníferas nos países desenvolvidos.

A massa específica também apresentou influência significativa na velocidade de propagação das ondas ultra-sônicas, comportando-se de modo diferenciado entre as espécies. O aumento da temperatura de secagem proporcionou, de modo geral, tendência de redução da velocidade ultra-sônica. A influência dessa variável, no entanto, foi reduzida. Devido à influência desses fatores, pode-se depreender que o aparelho de ultra-som deve ser calibrado para cada espécie ou grupo de espécies com comportamentos semelhantes.

A aplicação da técnica ultra-sônica na madeira mostra-se promissora. No entanto, há carência de estudos que relacionem o comportamento do ultra-som em função das diversas características relacionadas a esse material em madeiras de espécies tropicais, sendo a influência de algumas delas ainda não esclarecidas, o que é observado pelas divergências descritas entre os pesquisadores.

Apesar da existência de transdutores comerciais adequados à aplicação em madeiras, estudos fazem-se necessários para o correto uso da freqüência adequada às características do material e ao tamanho da peça avaliada, principalmente quando considerada a grande diversidade de espécies florestais existentes no Brasil.

\section{REFERÊNCIAS}

ALVEZ FILHO, M. Ultra-som é usado na avaliação de materiais. Jornal da Universidade Estadual de Campinas. Campinas, SP, 8 a 14 de setembro de 2003. Disponível em: $<$ http://www.unicamp.br/unicamp/ unicamp_hoje/jornalPDF/228-pag11.pdf>. Acesso em: 13/11/2004.

BARTHOLOMEU, A. Classificação de peças estruturais de madeira através do ultra-som. 105 f. Tese (Doutorado em Engenharia Agrícola) - Universidade de Campinas, Campinas, 2001.

BEKHTA, P.; NIEMZ, P.; KUCERA, L. The study of sound propagation in the wood-based composite materials. In: INTERNATIONAL SYMPOSIUM ON NONDESTRUCTIVE TESTING OF WOOD, 12, 2000, Suíça: Wood NDT-2000. Abstracts... Disponível em: <http://www.ndt.net/abstract/wood00/data/3.htm>. Acesso em: 10/09/2005. 
BRASHAW, B. K.; WANG, X.; ROSS, R. J.; PELLERIN, R. F. Relationship between stress wave velocities of green and dry veneer. Forest Products Journal, Madison, v. 54, n. 6, p. 85-89, 2004.

BUCUR, V. Wood structure anisotropy estimated by acoustic invariants. IAWA Bulletin, Leiden, v. 9, n. 1, p. 67-74, 1988.

CALEGARI, L. Uso da onda ultra-sônica como meio de controle do processo de secagem da madeira. 100 f. Dissertação (Mestrado em Engenharia Florestal) - Universidade Federal de Santa Maria, Santa Maria, RS, 2006.

COSTA, O. A. L. Velocidade de propagação de ondas de ultra-som na madeira para diferentes condições de umidade. $92 \mathrm{f}$. Tese (Doutorado em Engenharia Agrícola) - Universidade Estadual de Campinas, Campinas, SP, 2005.

DYK, H. V.; RICE, R. W. Ultrasonic wave velocity as a moisture indicator in frozen and unfrozen lumber. Forest Products Journal, Madison, v. 55, n. 6, p. 68-72, 2005.

GONÇALVES, R.; COSTA, O. A. L. Acompanhamento da secagem da madeira de pinus, eucalipto e embuia utilizando ultra-som. In: CONGRESSO IBERO-AMERICANO DE PESQUISA E DESENVOLVIMENTO DE PRODUTOS FLORESTAIS, 2., 2002, Curitiba. Anais... Curitiba: UFPR, 2002. p. 1-10.

GREEN, D. W.; WINANDY, J. E.; KRETSCHMANN, D. E. Mechanical properties of wood. In: USDA Forest Service, Forest Products Laboratory. Wood Handbook: Wood as an engineering material. Madison, Wiscousin: U.S. Department of Agriculture, p. 1-44, 1999a.

GREEN, D. W.; EVANS, J. W.; LOGAN, J. D.; NELSON, W. J. Adjusting modulus of elasticity for changes in temperature. Forest Products Journal, Madison, v. 49, n. 10, p. 82-94, 1999 b.

GRUNDSTRÖM, F. Non-destructive testing of particleboard with sound and eigen frequency methods. 60 f. Dissertação (Mestrado em Engenharia Mecânica) - Luleå University of Technology, Skellefteå, 1998 .

LORENZI, A. Aplicação de testes ultra-sônicos para avaliação de estruturas de concreto utilizando elementos de inteligência artificial. 152 f. Dissertação (Mestrado em Engenharia Civil) - Universidade Federal de Santa Maria, Santa Maria, RS, 2000.

NESVIJSKI, E. G. Dry point contact transducers: design for new applications. In: The e-Journal of Nondestructive Testing, v. 9, n. 9, Berlin: NDT.net, 2003. Disponível em: <http://www.ndt.net/article/ v08n09/nesvi/nevsi.htm>. Acesso em: 08/05/2008.

PUCCINI, C. T. Avaliação de aspectos de qualidade da madeira utilizando o ultra-som. 139 f. Tese (Doutorado em Engenharia Agrícola) - Universidade Estadual de Campinas, Campinas, SP, 2002.

SANTINI, E. J. Alternativas para monitoramento e controle do processo de secagem de madeira serrada em estufa. 198 f. Tese (Doutorado em Ciências Florestais) - Universidade Federal do Paraná, Curitiba, PR, 1996.

SHIMOYAMA, V. R. S. Estimativas de propriedades da madeira de Pinus taeda através do método não-destrutivo emissão de ondas de tensão, visando à geração de produtos de alto valor agregado. 151 f. Tese (Doutorado em Ciências Florestais) - Setor de Ciências Agrárias, Universidade Federal do Paraná, Curitiba, PR, 2005.

SIMPSON, W. T. Relationship between speed of sound and moisture content of red oak and hard maple during drying. Wood and Fiber Science, Madison, v. 30, n. 4, p. 405-413, 1998.

SIMPSON, T. S.; WANG, X. Relationship between longitudinal stress wave transit time and moisture content of lumber during kiln-drying. Forest Products Journal, Madison, v. 51, n. 10, p. 51-54, 2001.

WANG, S. Y.; LIN, C. J.; CHIU, C. M. The adjusted dynamic modulus of elasticity above the fiber saturation point in Taiwania plantation wood by ultrasonic-wave measurement. Holzforschung, Berlin, v. 57, n. 5 , p. 547-552, 2003. 